\title{
PRODUKSI JAGUNG MANIS DAN KADAR MINERAL JERAMI PADA TIGA MUSIM TANAM DENGAN PEMUPUKAN PUKAN 'PLUS'
}

\author{
Dwi Retno Lukiwati ${ }^{1)}$, Endang Dwi Purbayanti ${ }^{1)}$, Retno Iswarin Pujaningsih ${ }^{2)}$ \\ 1) Jurusan Pertanian, Fakultas Peternakan dan Pertanian, Universitas Diponegoro - Semarang \\ 2) Jurusan Peternakan, Fakultas Peternakan dan Pertanian, Universitas Diponegoro - Semarang \\ e-mail: drlukiwati_07@yahoo.com
}

\begin{abstract}
ABSTRAK
Tujuan penelitian untuk mengetahui pengaruh pupuk kandang (pukan) "plus" terhadap hasil jagung manis dan kadar mineral jerami pada tiga musim tanaman (MT). Penelitian dengan rancangan acak lengkap, tujuh perlakuan dan empat ulangan selama 70 hari. Perlakuan hanya diberikan pada MT-I yaitu To (pukan), T1 (pukan+EM4), T2 (pukan+starTmik), T3 (pukan+stardec), T4 (pukan granular+EM4), T5 (pukan granular+starTmik), and T6 (pukan granular+stardec). Hasil penelitian menunjukkan bahwa pukan berpengaruh tidak nyata terhadap hasil jagung manis. Kadar Ca dan P jerami lebih tinggi dengan pukan diinokulasi biodekomposer dibanding tanpa biodekomposer.
\end{abstract}

Kata kunci: biodekomposer, pupuk kandang, fosfor, jerami, Zea mays saccharata

\section{PENDAHULUAN}

Sistem integrasi tanaman - ternak (SITT) telah lama diterapkan dan dicirikan oleh keterkaitan antara tanaman pertanian dengan ternak. Hasil utama tanaman pertanian misalnya jagung manis untuk pangan, jerami sebagai pakan sedangkan limbah peternakan (feses, urine, sisa pakan) dapat dimanfaatkan sebagai pupuk kandang (pukan) untuk memperbaiki kesuburan tanah. Lahan untuk budidaya tanaman pangan pada umumnya defisiensi unsur hara fosfor dan memerlukan pemupukan organik maupun anorganik. Jagung manis (Zea mays saccharata) termasuk salah satu tanaman uji yang responsif terhadap pemupukan.

Tanah defisiensi fosfor selama ini diatasi dengan pemupukan superfosfat (SP) (Lukiwati, 2002; Kasno et al., 2006) untuk meningkatkan ketersediaan unsur hara P. Telah diketahui bahwa bahan baku pupuk SP adalah batuan fosfat (BP) direaksikan dengan asam sulfat, sehingga cepat tersedia bagi akar tanaman karena dapat larut dalam air. Oleh karena itu produksi jagung lebih tinggi apabila dipupuk SP dibanding BP yang bersifat lambat tersedia karena tidak larut dalam air (Lukiwati, 2002). Namun harga pupuk SP (36\% P2O5) lebih mahal (Rp. 20.000,-/kg) dibanding BP (Rp 3.500,-) bahkan langka ketika dibutuhkan. Maka kini saatnya beralih menggunakan pupuk BP (27\% P2O5) dengan menerapkan teknologi asidifikasi alami.

Pupuk BP berasal dari batuan fosfat digiling halus, mengandung trikalsium fosfat atau $\mathrm{Ca}_{3}\left(\mathrm{PO}_{4}\right) 2$. Pupuk BP tidak larut dalam air, tetapi larut dalam asam (Dierolf et al. 2001; Lukiwati et al. 2001). Pupuk BP sesuai diterapkan pada tanah masam (pH $<5,5$ ) dengan dosis $1-1,5$ ton $\mathrm{BP} / \mathrm{ha}$ atau $300-450 \mathrm{~kg}$
P2O5/ha (Dierolf et al. 2001). Dosis pupuk BP sekali pemberian sebanyak $500 \mathrm{~kg} \mathrm{P} 2 \mathrm{O}_{5} / \mathrm{ha}$ untuk masa tanam 5 tahun, menghasilkan produksi jagung ratarata meningkat 50\% dibanding tanpa pemupukan P (Sharma et al. 2001). Nassir (2001) juga meneliti dengan satu kali pemberian pupuk BP dosis $80-360 \mathrm{~kg}$ $\mathrm{P}_{2} \mathrm{O} 5 /$ ha, dapat meningkatkan produksi jagung setara atau bahkan lebih tinggi dibanding pemupukan SP. Efisiensi pemupukan $\mathrm{P}$ untuk produksi biji tertinggi dicapai pada dosis $66 \mathrm{~kg} \mathrm{P} / \mathrm{ha}$ atau $150 \mathrm{~kg} \mathrm{P} 2 \mathrm{O}_{5} / \mathrm{ha}$ (Lukiwati, 2002).

Telah diketahui bahwa ketika dilakukan pemupukan $\mathrm{P}$, tidak semuanya dapat diabsorbsi oleh akar tanaman, sehingga masih terdapat residu $P$ di dalam tanah dan masih berpengaruh selama beberapa tahun (Dierolf et al. 2001). Nilai residu pemupukan BP dengan satu kali pemberian $120 \mathrm{~kg}$ P/ha (275 kg P2O5/ha) setara hasilnya dengan dosis yang sama tetapi terbagi dalam 3 kali pemberian (Friesen et al. 1990). Residu pemupukan P pada musim tanam pertama (MT-1) dengan dosis $132 \mathrm{~kg}$ $\mathrm{P} / \mathrm{ha}$ (293 kg P2O5/ha) masih mampu menghasilkan produksi biji dan bahan kering jerami jagung varietas Bisma lebih tinggi pada musim tanam kedua (MT-2) dibanding tanpa pemupukan P. Namun hasil jagung pada MT-2 lebih rendah dibanding MT-1. Pupuk BP menghasilkan produksi biji dan bahan kering jerami jagung setara dengan pupuk SP pada MT-2 (Lukiwati dan Waluyanti, 2001). Residu pemupukan P pada sistem tanam jagung secara rotasi dengan gandum masih menghasilkan produksi jagung lebih tinggi dibanding tanpa pemupukan P (Stoyanov, 2001).

Limbah usaha peternakan sapi potong yaitu feses bercampur urin dan sisa pakan dapat dimanfaatkan sebagai pupuk kandang (pukan) melalui proses 
dekomposisi agar rasio $\mathrm{C} / \mathrm{N}$ dibawah 20, dan dapat dipercepat dengan inokulasi mikroba dekomposer (Edesi et al., 2012). Feses sapi juga mengandung bakteri dan cendawan decomposer sehingga dapat mempercepat proses dekomposisi bahan organik (Saraswati dan Sumarno, 2008). Pupuk kandang dapat meningkatkan populasi bakteri dalam tanah sebanyak 0,02\% (Azotobacter) dan 0,46\% (Azospirillum) (Mujiyati dan Supriyadi, 2009). Mikroba perombak bahan organik telah tersedia secara komersial antara lain EM-4, stardec, dan starTmik. Pupuk kandang (sapi) selain mengandung unsur hara $\mathrm{N}, \mathrm{P}$, dan $\mathrm{K}$ masing-masing 0,55; 0,12 dan 0,30 \% (Soelaeman, 2008), juga asam-asam humat dan fulfat yang dapat meningkatkan kelarutan pupuk BP (Sumida dan Yamamoto, 1997). Oleh karena itu penambahan BP dalam proses dekomposisi pukan akan meningkatkan kelarutan BP dan dapat meningkatkan kualitas jerami jagung manis (Lukiwati, 2012). Genus fungi yang terdapat pada hasil dekomposisi campuran feses segar dan batuan fosfat adalah Chytridium sp., Aspergillus sp., Rhizopus sp. dan Fusarium sp (Nugroho et al., 2013). Pupuk kandang berperan dalam meningkatkan kesuburan fisik tanah karena mampu meningkatkan agregat ruang pori, ketersediaan air dan aerasi tanah (Jamariah dan Sulichantini, 2004). Disamping itu, telah dibuktikan bahwa pukan dapat meningkatkan kandungan $\mathrm{N}$ total tanah (Mujiyati dan Supriyadi, 2009). Produksi padi dengan aplikasi pukan di inokulasi biodekomposer, menunjukkan berbeda tidak nyata secara statistik dibanding tanpa biodekomposer, masing-masing 2,25 t/ha dan 2,19 ton/ha. Aplikasi biodekomposer berpengaruh nyata terhadap peningkatan kandungan $\mathrm{P}$ daun (Nurrahma dan Melati, 2012).

Berdasarkan uraian tersebut di atas, maka pupuk BP dapat digunakan sebagai sumber P untuk meningkatkan kualitas pukan dan dipercepat proses dekomposisinya dengan inokulasi biodekomposer. Pukan tersebut selanjutnya dibuat dalam bentuk granular, sehingga memudahkan penggunaan, pengemasan, dan penyimpanan. Pukan diperkaya BP (pukan plus) bersifat "slow release" sehingga masih terdapat residu yang bermanfaat untuk musim tanam berikutnya. Oleh karena itu, penelitian dilakukan untuk mengetahui pengaruh beberapa jenis pukan plus dan efek residunya terhadap produksi jagung manis, kadar Ca dan $\mathrm{P}$ jerami sampai dengan tiga musim tanam.

\section{MATERI DAN METODE}

\section{Materi Penelitian}

Penelitian telah dilaksanakan selama tiga musim tanam pada tanah vertisol di Kabupaten Sragen (Jawa
Tengah). Materi yang digunakan adalah benih jagung manis (Zea mays saccharata), urea ( $46 \% \mathrm{~N}), \mathrm{KCl}(50 \%$ K2O), BP (27\% P2O5) dan pupuk kandang diperkaya BP (pukan plus) sebanyak 7 macam. Biodekomposer yang digunakan adalah starTmik, stardec dan EM-4 untuk mempercepat proses dekomposisi.

\section{Persiapan dan Pelaksanaan Penelitian}

Media tanam sebanyak 28 petak, masing-masing ukuran $3 \mathrm{~m} \times 2,5 \mathrm{~m}$ sehingga luas tiap petak 7,5 $\mathrm{m}^{2}$. Pembuatan 7 macam pukan diperkaya BP dan hanya satu pukan tanpa biodekomposer sedangkan 6 macam pukan lainnya diinokulasi biodekomposer EM-4, starTmik dan stardec, masing-masing 2 pot. Tiga dari 6 macam pukan tersebut dibuat bentuk granular. Pembuatan 7 macam pukan dengan penambahan BP (batuan fosfat digiling halus) masing-masing setara $66 \mathrm{~kg} \mathrm{P} / \mathrm{ha}\left(150 \mathrm{~kg} \mathrm{P}_{2} \mathrm{O} 5 /\right.$ ha) pada waktu proses pembuatan pukan 30 t/ha. Analisis kimia pukan dan tanah dilakukan sebelum penelitian dilaksanakan. Perlakuan pukan plus yaitu To (pukan), T1 (pukan+EM4), T2 (pukan+starTmik), $\mathrm{T} 3$ (pukan+stardec), T4 (pukan granular+EM4), T5 (pukan granular +starTmik), T6 (pukan granular +stardec). Semua petak penelitian diberi urea 200 $\mathrm{kg} \mathrm{N} / \mathrm{ha}$ dan $\mathrm{KCl} 125 \mathrm{~kg} \mathrm{~K} / \mathrm{ha}(150 \mathrm{~kg} \mathrm{~K} 2 \mathrm{O} / \mathrm{ha}$ ) sebagai pupuk dasar sesuai rekomendasi Lukiwati et al. (2010).

\section{Pelaksanaan}

Pukan plus hanya diberikan pada MT-1, sedangkan urea dan $\mathrm{KCl}$ setiap kali musim tanam. Penanaman 2 benih jagung manis tiap lubang tanam, dengan jarak tanam $40 \mathrm{~cm} \times 30 \mathrm{~cm}$. Panen jagung dan pemotongan jerami dilakukan pada umur 70 hari setelah tanam, dilanjutkan penimbangan tongkol jagung berklobot tiap petak. Dilanjutkan analisis kadar Ca dan P jerami (Islam et al. (1992).

\section{Analisis Data}

Data produksi tongkol jagung manis berklobot dan kadar P dan Ca jerami di analisis ragam untuk mengetahui pengaruh perlakuan yang diberikan, dilanjutkan uji wilayah ganda Duncan (DMRT) untuk mengetahui perbedaan antar perlakuan terhadap parameter yang diamati.

\section{HASIL DAN PEMBAHASAN}

\section{Hasil Analisis Pukan dan Tanah}

Hasil analisis tanah awal penelitian, menunjukkan bahwa status hara tanah termasuk defisien unsur hara P. Hasil analisis pukan plus menunjukkan bahwa kadar P tersedia pada pukan dengan inokulasi stardec maupun EM-4 tidak berbeda, masing-masing 2083,13 
ppm dan 2083,13 ppm, namun lebih tinggi dibanding tanpa biodekomposer (2006,61 ppm), demikian juga terhadap starTmik (1915,27 ppm). Sedangkan $\mathrm{P}$ tersedia dalam pukan tanpa biodekomposer lebih tinggi dibanding pukan diinokulasi starTmik. Dinamika fosfor dalam tanah sangat komplek, karena melibatkan proses kimia maupun biologi (Bationo dan Kumar, 2002).

Hasil analisis pukan plus mempunyai $\mathrm{C} / \mathrm{N}$ ratio dibawah 20. Dengan demikian proses dekomposisi telah berlangsung dengan baik (Prihandini dan Purwanto, 2007). Dekomposisi pukan tanpa inokulasi biodekomposer (To) mampu menghasilkan ratio $\mathrm{C} / \mathrm{N}$ dibawah 20, karena feses juga mengandung bakteri maupun cendawan dekomposer (Saraswati dan Sumarno, 2008). Terdapat perbedaan status nutrisi antara pukan di inokulasi biodekomposer dan tanpa biodekomposer. Dengan demikian, masing-masing mikroba dekomposer tidak sama pengaruhnya terhadap nutrisi hasil dekomposisi proses pembuatan pukan plus.

\section{Produksi Tongkol Jagung Manis}

Hasil analisis ragam menunjukkan bahwa pukan plus berpengaruh tidak nyata terhadap produksi tongkol jagung berkelobot pada tiga musim tanam (MT-1, MT-2, MT-3). Data Tabel 1 menunjukkan bahwa produksi tongkol jagung tidak dipengaruhi oleh berbagai macam pukan plus (pukan diperkaya BP).

Pukan plus granular maupun non-granular dengan maupun tanpa biodekomposer, dan efek residunya setara kemampuannya dalam menghasilkan produksi tongkol jagung sampai dengan tiga musim tanam. Hal ini disebabkan karena kandungan unsur hara N, $\mathrm{P}$, dan $\mathrm{K}$ berbagai macam pukan tersebut cenderung tidak berbeda (data tidak ditampilkan).

Tabel 1. Produksi Tongkol Jagung Manis pada Tiga Musim Tanam dengan Pemupukan Beberapa Macam Pukan Plus

\begin{tabular}{lccc}
\hline \multirow{2}{*}{ Perlakuan Pemupukan } & MT-1 & MT-2 & MT-3 \\
\cline { 2 - 4 } & (kg/petak) & (kg/petak) & (kg/petak) \\
\hline T0. Pukan & 18,31 & 20,97 & 17,15 \\
T1. Pukan+EM4 & 17,28 & 22,59 & 17,33 \\
T2. Pukan+Stardec & 18,09 & 22,23 & 15,63 \\
T3. Pukan+StarTmik & 17,28 & 22.77 & 16,56 \\
T4. Pukan granular+EM4 & 15,57 & 19,89 & 18,86 \\
T5. Pukan granular+Stardec & 18,72 & 22,05 & 16,11 \\
T6. Pukan granular+StarTmik & 15,25 & 24,48 & 16,02 \\
\hline
\end{tabular}

Semua pukan yang diberikan pada MT-1 diperkaya dengan BP. Lukiwati dan Waluyanti (2001) menyatakan bahwa efek residu pupuk P (MT-2) menghasilkan produksi jagung tidak berbeda dibanding MT1. Pupuk kandang dapat meningkatkan populasi bakteri sebanyak 0,02\% (Azotobacter) dan 0,46\%
(Azospirillum) dalam tanah (Mujiyati dan Supriyadi, 2009). Pukan mengandung mikroba dekomposer alami yang aktif dalam proses dekomposisi (Saraswati dan Sumarno, 2008), sehingga pukan plus tersebut maupun efek residunya setara pengaruhnya terhadap produksi tongkol jagung. Pupuk kandang berperan dalam meningkatkan kesuburan fisik tanah karena meningkatkan plastisitas, agregat pori tanah, ketersediaan air dan aerasi tanah (Jamariah dan Sulichantini, 2004) dan mempunyai kemampuan sama dalam meningkatkan pertumbuhan dan produksi tanaman (Nurrahma dan Melati, 2012).

\section{Kadar Fosfor dan Kalsium Jerami Jagung Ma- nis}

Hasil analisis ragam menunjukkan bahwa pukan plus yang diberikan pada MT-1, berpengaruh nyata terhadap kadar $\mathrm{P}$ dan Ca jerami hingga tiga musim tanam (MT-1, MT-2, MT-3). Data Tabel 2 dan Tabel 3 menunjukkan bahwa pukan granular dan non-granular dengan maupun tanpa biodekomposer, menghasilkan kadar P (kecuali T6) dan Ca berbeda tidak nyata pada MT-1. Pupuk kandang mengandung biodekomposer alami yang aktif dalam proses dekomposisi (Saraswati dan Sumarno, 2008), sehingga ketika pukan di inokulasi dengan dekomposer serta dibentuk granular maupun non-granular tidak nyata pengaruhnya terhadap kadar P jerami. Genus fungi yang terdapat pada hasil dekomposisi campuran feses segar dan batuan fosfat adalah Chytridium sp., Aspergillus sp., Rhizopus sp. dan Fusarium sp (Nugroho et al., 2013). Dengan demikian, beberapa macam pukan plus tersebut setara kemampuannya dalam menghasilkan kadar P dan Ca jerami pada MT-1.

Tabel 2. Kadar Fosfor Jerami Jagung Manis Pada Tiga Musim Tanam dengan Pemupukan Beberapa Macam Pukan Plus

\begin{tabular}{lccc}
\hline \multicolumn{1}{c}{ Perlakuan Pemupukan } & $\begin{array}{c}\text { MT-1 } \\
(\%)\end{array}$ & $\begin{array}{c}\text { MT-2 } \\
(\%)\end{array}$ & $\begin{array}{c}\text { MT-3 } \\
(\%)\end{array}$ \\
\hline T0. Pukan & $0,56 \mathrm{a}$ & $0,24 \mathrm{~d}$ & $0.37 \mathrm{c}$ \\
T1. Pukan+EM4 & $0,48 \mathrm{ab}$ & $0,33 \mathrm{c}$ & $0.42 \mathrm{bc}$ \\
T2. Pukan+Stardec & $0,51 \mathrm{ab}$ & $0,33 \mathrm{c}$ & $0.41 \mathrm{c}$ \\
T3. Pukan+StarTmik & $0,55 \mathrm{a}$ & $0.38 \mathrm{~b}$ & $0.40 \mathrm{c}$ \\
T4. Pukan granular+EM4 & $0,47 \mathrm{ab}$ & $0,38 \mathrm{~b}$ & $0.50 \mathrm{a}$ \\
T5. Pukan granular+Stardec & $0,43 \mathrm{ab}$ & $0,37 \mathrm{~b}$ & $0.48 \mathrm{ab}$ \\
T6. Pukan granular+StarTmik & $0,39 \mathrm{~b}$ & $0,43 \mathrm{a}$ & $0.44 \mathrm{~b}$ \\
\hline
\end{tabular}

* Superskrip berbeda pada kolom yang sama, menunjukkan berbeda nyata pada taraf 5\% dengan uji DMRT.

Namun demikian, pada MT-2 dan MT-3 pukan granular menghasilkan kadar $\mathrm{P}$ dan Ca jerami nyata lebih tinggi dibanding non-granular. Dengan demikian pukan granular dengan inokulasi biodekomposer mampu menghasilkan kadar P dan Ca jerami nyata lebih tinggi dibanding pukan non granular pada MT-2 dan MT-3. Beberapa hasil penelitian serupa antara lain disampaikan Jamaludin (2006) bahwa pukan 
Tabel 3. Kadar Kalsium Jerami Jagung Manis Pada Tiga Musim Tanam dengan Pemupukan Beberapa Macam Pukan Plus

\begin{tabular}{lccc}
\hline \multicolumn{1}{c}{ Perlakuan Pemupukan } & $\begin{array}{c}\text { MT-1 } \\
(\%)\end{array}$ & $\begin{array}{c}\text { MT-2 } \\
(\%)\end{array}$ & $\begin{array}{c}\text { MT-3 } \\
(\%)\end{array}$ \\
\hline T0. Pukan & $0,19 \mathrm{ab}$ & $0,27 \mathrm{c}$ & $0.17 \mathrm{~b}^{*}$ \\
T1. Pukan+EM4 & $0,30 \mathrm{a}$ & $0,36 \mathrm{~b}$ & $0.24 \mathrm{a}$ \\
T2. Pukan+Stardec & $0,18 \mathrm{ab}$ & $0,40 \mathrm{~b}$ & $0.17 \mathrm{~b}$ \\
T3. Pukan+StarTmik & $0,17 \mathrm{~b}$ & $0.39 \mathrm{~b}$ & $0.19 \mathrm{~b}$ \\
T4. Pukan granular + EM4 & $0,20 \mathrm{ab}$ & $0,53 \mathrm{a}$ & $0.24 \mathrm{a}$ \\
T5. Pukan granular+Stardec & $0,24 \mathrm{ab}$ & $0,54 \mathrm{a}$ & $0.21 \mathrm{ab}$ \\
T6. Pukan granular + & $0,25 \mathrm{ab}$ & $0,45 \mathrm{ab}$ & $0.24 \mathrm{a}$ \\
StarTmik & &
\end{tabular}

* Superskrip berbeda pada kolom yang sama, menunjukkan berbeda nyata pada taraf $5 \%$ dengan uji DMRT.

granular mampu meningkatkan pertumbuhan dan hasil tanaman padi. Pukan granular dengan inokulasi biodekomposer mampu meningkatkan produktivitas tanah melalui proses mikrobiologis tanah dan berfungsi sebagai stabilisator unsur hara dengan merangsang jasad mikro yang mampu mengikat partikel tanah sehingga dapat memperbaiki struktur tanah (Komposindo Granular-Arendi, 2005). Lukiwati dan Pujaningsih (2015) menyatakan bahwa pukan granular mampu menekan terjadinya pencucian unsur hara yang terkandung dalam pukan tersebut, sehingga kadar P dan Ca jerami lebih tinggi dibanding non-granular pada musim tanam berikutnya.

Pupuk kandang berperan dalam meningkatkan kesuburan fisik tanah karena meningkatkan plastisitas, agregat pori tanah, ketersediaan air dan aerasi tanah (Jamariah dan Sulichantini, 2004) dan mempunyai kemampuan sama dalam meningkatkan pertumbuhan dan produksi tanaman (Nurrahma dan Melati, 2012). Pukan granular maupun non-granular serta di inokulasi maupun tanpa biodekomposer, masingmasing setara kemampuannya dalam menghasilkan produksi tongkol jagung manis maupun kadar $\mathrm{P}$ dan Ca jerami pada MT-1.

Namun demikian, efek residu pukan granular di inokulasi biodekomposer menghasilkan kadar P dan Ca jerami lebih tinggi dibanding pukan non-granular dengan maupun tanpa biodekomposer pada MT-2 dan MT-3. Meskipun feses sapi juga mengandung bakteri maupun cendawan dekomposer (Saraswati dan Sumarno, 2008), namun belum mampu meningkatkan absorbsi unsur hara P dan Ca setara dengan mikroba dekomposer yang diinokulasikan (EM-4, starTmik dan stardec) pada pukan granular. Pengaruh pukan granular dan non-granular di inokulasi maupun tanpa biodekomposer serta efek residunya, masing-masing setara kemampuannya dalam menghasilkan produksi jagung pada MT-1, MT-2 dan MT-3, serta kadar P dan Ca jerami pada MT-1. Namun pukan granular mampu menghasilkan kadar $\mathrm{P}$ dan Ca jerami lebih tinggi dibanding non-granular pada MT-2 dan MT-3.

\section{SIMPULAN}

Pukan diperkaya fosfat alam (pukan plus) maupun efek residunya, setara kemampuannya dalam menghasilkan produksi tongkol jagung manis, kadar $\mathrm{P}$ dan Ca jerami pada MT-1. Efek residu pukan plus di inokulasi biodekomposer mampu menghasilkan kadar P dan Ca jerami lebih tinggi dibanding tanpa biodekomposer pada MT-2 dan MT-3. Efek sisa pukan plus bentuk granular, menghasilkan produksi kadar $\mathrm{P}$ dan Ca jerami lebih tinggi disbanding non-granular.

\section{UCAPAN TERIMA KASIH}

Terima kasih kepada Ditlitabmas Ditjen Dikti Kemendikbud - BOPTN TA 2013-2015 atas dana penelitian melalui DIPA Universitas Diponegoro. Terima kasih kepada Kepala Dinas Peternakan dan Perikanan, serta Kelompok Peternak "Sumber Subur" Kecamatan Kedawung Kabupaten Sragen, yang telah membantu dalam pelaksanaan penelitian ini hingga dapat diselesaikan dengan baik. Terima kasih kepada Edi, Adira, Hendra dan Lutfiana yang telah membantu pelaksanaan penelitian di lapang.

\section{REFERENSI}

Bationo, A. dan Kumar, A.K. 2002. Phosphorus use effiency as related to sources of $\mathrm{P}$ fertilizers, rainfall, soil, crop management, and genotypes in the West African semiarid tropics. Proc. of Food Security in NutrientStressed Environments: Exploiting Plants Genetic Capabilities. International Crops Research Institute o Semi-Arid Tropics (ICRISAT). Patancheru, India. Kluwer Academic Publishers. Printed in Netherlands. p.145-154.

Dierolf, T., Fairhurst, T., and Mutert, E. 2001. Soil Fertility Kit. A toolkit for acid, upland soil fertility management in Southeast Asia. First edition. Printed by Oxford Graphic Printers.

Edesi, L., Jarvan, M., Noormeths, M., Lauringson, E., Adamson, A., dan Akk, E. 2012. The importance of soil cattle manure application on soil microorganism inorganic and conventional cultivation. Acta Agric. Scandinavida. Section B - Soil \& Plant Sci. 62(7): 583-594.

Friesien, D. K., Adiningsih, J. S., Sudjadi, M., and Partohardjono, S. 1990. Reactive phosphate rock as alternative P sources for upland crops on Sumatra soils. Prosiding Lokakarya Nasional Efisiensi Penggunaan Pupuk V. Puslitan dan Agroklimat. Cisarua. p. 367-379.

Islam, A. K.M. S., Kerven, G., and Oweczkin, J. 1992. Methods of Plant Analysis. ACIAR 8904 IBSRAM QC. Department of Agric., The University of Queensland, Australia. 
Jamaludin, L. 2005. Pengaruh kombinasi pupuk organik dan N, P, K terhadap pertumbuhan dan hasil tanaman padi sawah (Oryza sativa L.) varietas Ciherang di lahan sawah irigasi. Fakultas Pertanian. Unsika. Karawang.

Jamariah dan Sulichantini, E. D. 2004. Pengaruh pemberian pupuk kandang ayam dan media tanam terhadap pertumbuhan dan hasil tanaman bawang sabrang (Eleutherine americana L.). J. Budidaya Pertanian, 10(2): 88-93.

Kasno, A., Setyorini, D., dan Tuberkih, E. 2006. Pengaruh pemupukan fosfat terhadap produktivitas tanah Inceptisol dan Ultisol. J. Ilmu-Ilmu Pertanian Indonesia. 8(2):91-98.

Komposindo Granular Arendi. 2005. Kompos granular rabog. PT Komposindo Granular Arendi.

Lukiwati, D. R., Ekowati, R., dan Karno. 2001. Produksi bahan kering dan kadar protein kasar rumput setaria gajah dengan pemupukan $\mathrm{N}$ dan P. Abstr.167. Seminar Nasional Pengembangan Peternakan Berbasis Sumberdaya Lokal. Fakultas Peternakan IPB, Bogor, 8-9 Agustus.

Lukiwati, D. R. 2002. Effect of rock phosphate and superphosphate fertilizer on the productivity of maize var. Bisma. Proc.of International Workshop Food Security in Nutrient-Stressed Environments: Exploiting Plant's Genetic Capabilities. International Crops Research Institute for Semi-Arid Tropics (ICRISAT). Patancheru, India, 27-30 September 1999. Kluwer Academic Publishers. Netherlands. p. 183-187.

Lukiwati, D. R., dan Pujaningsih, R. I. 2015. Efek sisa pupuk kandang diperkaya fosfat alam dalam bentuk granular dan di inokulasi biodekomposer terhadap nutrisi jerami jagung manis di lahan kering. J. Tumbuhan Pakan Tropik. PASTURA. 4(2): 78-82.

Lukiwati, D. R., Surahmanto, and B. A. Kristanto. 2010. Production and nutrient uptake improvement of sweet corn by rock phosphate combined with manure and mycorrhiza inoculation. Abstr.p.80. International Conference on Balanced Nutrient Management for Tropical Agriculture. Kuantan, Pahang. Malaysia, 12-16 April.

Lukiwati, D. R., dan Waluyanti, R. 2001. Response of maize to the residual effect of phosphorus fertilization in Latosolic soil. In: $37^{\text {th }}$ Croatian Symposium on Agriculture with an International Participation. Opatija-Croatia, 19-23 February. p.183.

Mujiyati dan Supriyadi. 2009. Pengaruh pupuk kandang dan NPK terhadap populasi bakteri Azotobacter dan Azospirillum dalam tanah pada budidaya cabai (Capsicum annum) Bioteknologi. 6(2): 63-69.

Nassir, A. 2001. IMPHOS experience on direct application of phosphate rock in Asia. In Rajan SSS, Chien SH (eds.). Proc.of an International Meeting "Direct Application of Phosphate Rock and Related Appropriate Technology" - Latest Developments and Practical Experiences. IFDC/ MSSS/ESEAP/PPI-PPIC. Kuala Lumpur, 16-20 July. p. 110-122.

Nugroho, S., Dermiyati, G., Lumbanraja, J., Triyono, S., Ismono, H., Ningsih, M. K., dan Saputra, F. Y. 2013. Inoculation effect of N2-Fixer and P-solubilizer into a mixture of fresh manure and phosphate rock formulated as organonitrofos fertilizer on bacterial and fungal populations. J. Trop. Soils. 18(1): 75-80.

Nurrahma, A. H. I., dan Melati, M. 2012. The influence of fertilizer type and decomposer on organic rice growth and yield. J. Agrohorti, 1(1): 1.

Prihandini, P. W. dan Purwanto, T. 2007. Petunjuk Teknis Pembuatan Kompos Berbahan Kotoran Sapi. Pusat Penelitian dan Pengembangan Peternakan, Grati.

Saraswati, R., dan Sumarno. 2008. Pemanfaatan mikroba penyubur tanah. Iptek Tanaman Pangan. 3(1): 1-58.

Sharma, P.K., Bhardwaj, S.K., and Sharma, H.L. 2001. Long-term a studies on agronomic effectiveness of African and Indian phosphate rocks in relation to productivity of maize and wheat crops in mountain acid soils of Western Himalayas (India). In Rajan SSS, Chien SH (eds.). Proc.of International Meeting "Direct Application of Phosphate Rock and Related Appropriate Technology-Latest Developments and Practical Experiences. IFDC/MSSS/ESEAP. Kuala Lumpur, 16-20 July. p. 322-328.

Stoyanov, I. 2001. Systematic mineral fertilization on maize, cultivated in a 4-field crop rotation. $37^{\text {th }}$ Croation Symposium on Agric. with an International Participation. Collection of Summaries. Opatija, Croatia. February 19-23. Abstr. p.195.

Sumida, H., and Yamamoto, K. 1997. Effect of decomposition of city refuse compost on the behaviour of organic compounds in the particle size fractions. Proc. 13th Internatal. Plant Nutr. Colloq. Tokyo. p.599-60o. 